\title{
Advanced Endwall Contouring for Loss Reduction and Outflow Homogenization for an Optimized Compressor Cascade
}

\author{
Oliver Reutter *, Magdalena Rozanski, Alexander Hergt * and Eberhard Nicke \\ German Aerospace Center DLR, Institute of Propulsion Technology, Department Fan and Compressor, \\ 51170 Köln, Germany; magdalena.rozanski@dlr.de (M.R.); eberhard.nicke@dlr.de (E.N.) \\ * Correspondence: oliver.reutter@dlr.de (O.R.); alexander.hergt@dlr.de (A.H.) \\ Academic Editor: Marcello Manna \\ Received: 15 September 2016; Accepted: 23 February 2017; Published: 16 March 2017
}

\begin{abstract}
The following paper deals with the development of an optimized non-axisymmetric endwall contour for reducing the total pressure loss and for homogenizing the outflow of a highly-loaded compressor cascade. In contrast to former studies using a NACA-65 K48 cascade airfoil this study starts with the design of a new high-performance airfoil which is based on the aerodynamic boundary conditions of the NACA-65 K48 cascade. This new airfoil is then used as a basis. Optimizations of the airfoil and of the endwall contour are performed using the German Aerospace Center (DLR) in-house tool AutoOpti and the RANS (Reynolds-averaged Navier-Stokes)-solver TRACE (Turbomachinery Research Aerodynamic Computational Environment). Three operating points at an inflow Mach number of 0.67 with different inflow angles are used to secure a wide operating range. The optimized endwall contour changes the secondary flow in such a way that the corner stall is reduced which, in turn, significantly reduces the total pressure loss. The endwall contour in the outflow region leads to a considerable homogenization of the outflow in the near wall region. Using non-axisymmetric endwall shaping demonstrates a valuable measure to further improve highly-efficient compressor blading on the vane level.
\end{abstract}

Keywords: compressor; CFD; optimization; endwall contouring; cascade; outflow angle; overturning; secondary flow; corner stall

\section{Introduction}

As compressors become more and more advanced, and in order to raise the efficiency and to widen the operating range, the design space has to be enlarged and three-dimensional design features have to be taken into account. With improved code predictability and increased loading levels, the control of secondary flows is of the highest importance. These losses are especially important in the rear stages of high-pressure compressors, where low aspect ratios prevail. Investigations by Scholz [1] in cascades for an aspect ratio of one show that secondary flow losses can reach up to $60 \%$ of the total losses. Next to the possibility of three-dimensional blade shaping, like sweep or lean, a good additional option for designing compressors is to use endwall contouring (EWC) and shape the endwall three-dimensionally. This allows influencing the secondary flow passively, thereby reducing the losses significantly. Early designs were axisymmetric, like in the patents of Spear and Biedermann [2] or of Hoeger and Schmidt-Eisenlohr [3]. Later works used non-axisymmetric attempts, like in the works of Harvey [4], Harvey and Offord [5], Iliopoulou et al. [6], Reising and Schiffer [7,8], Dorfner [9], Dorfner et al. [10], or Heinichen et al. [11]. Overviews of EWC are given in Gier et al. [12] and Harvey [4]. 
While Reutter et al. [13] used a NACA 65 K48 airfoil (National Advisory Committee for Aeornautics) as a base configuration for EWC in a cascade, this study uses an optimized airfoil. It is the next step in the DLR research on endwall contouring. Numerical studies are made where, as a first step, an airfoil is optimized, which is then used for optimization of the endwall for a cascade geometry. The endwall optimization is used not only in order to reduce the losses, but also to homogenize the exit flow angle for beneficial effects on a hypothetical next stage or on the combustion chamber. No 3D design of the blade was used in order to be better comparable to the former study [13], as well as to separate the relevant effects. Even using a 3D design would not have suppressed all of the secondary flow and influencing this is the main study focus and the main effect of EWC.

\section{Numerical Setup}

\subsection{Optimization Tool AutoOpti}

For the optimization the DLR in-house tool AutoOpti was used, described by Voss et al. [14], Siller et al. [15], and Aulich and Siller [16]. It is a multi-objective evolutionary algorithm using embedded metamodels with the expected volume gain method, described by Voss et al. [17].

Figure 1 shows the flowchart of the optimization. The master works in the same way for both cases, airfoil or endwall design. It ranks the different geometries, called members, and stores them in a database. It uses this database together with metamodels and/or an evolutionary algorithm in order to give new promising geometries to the slaves to be calculated.

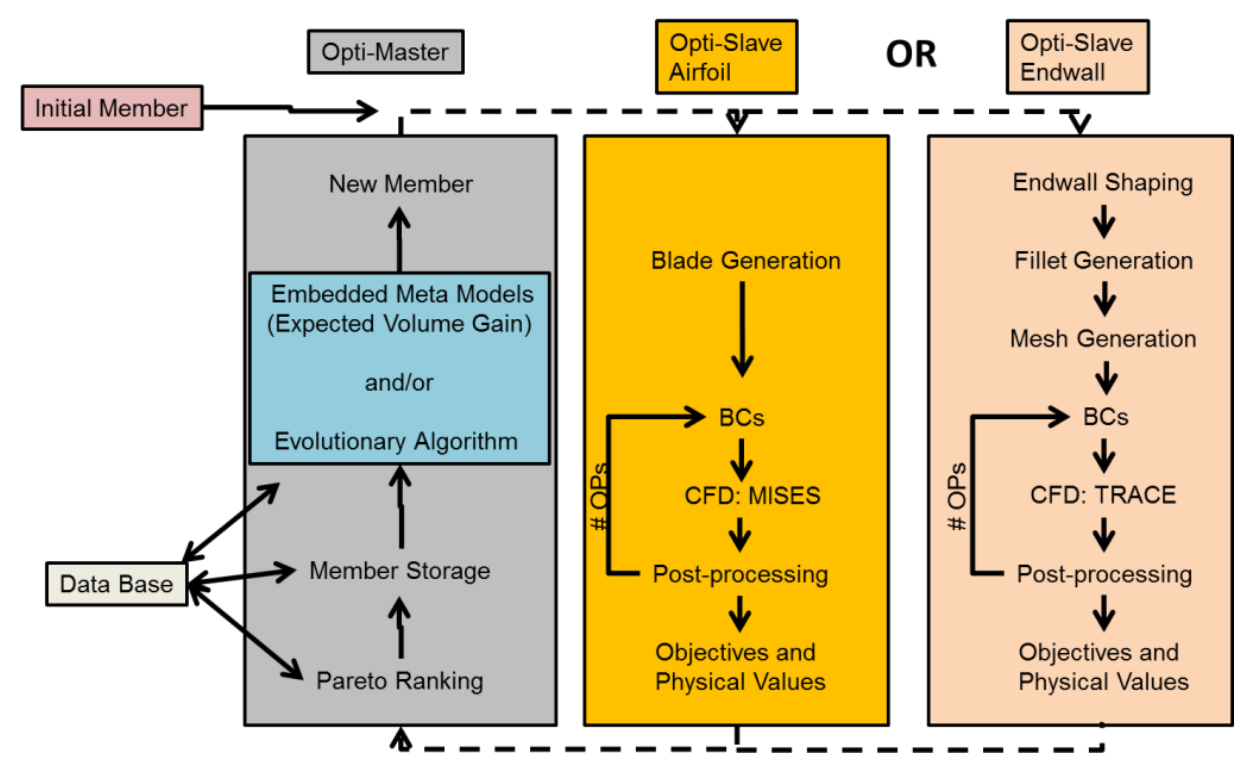

Figure 1. Flowchart of the optimization. The airfoil optimization uses the slave process chain in the middle; the endwall optimization uses the slave process chain on the right.

As it is very flexible, the same optimizer can be used for the airfoil optimization and the endwall optimization. Several slave processes working in parallel are controlled by one master process. All slaves during an optimization use the same process chain. In the case of the airfoil optimization the process chain shown in the middle of Figure 1 is used by the slaves. For the airfoil optimization each slave creates an airfoil geometry by the DLR in-house tool BladeGenerator, and then calculates the aerodynamic behavior for the given operating points with the 2D flow solver MISES, described by Youngren and Drela [18], which incorporates a mesh generation.

For the endwall optimization all slaves use the process chain shown on the right hand side of Figure 1. Here, a certain airfoil is used to generate a cascade configuration with endwalls. The geometry of the endwall is varied and a $2 \mathrm{~mm}$ radius fillet is added between the endwall and the cascade vane. 
After the mesh generation the flow in each operating point is calculated with the DLR in-house 3D-CFD-solver TRACE. More details can be found in Becker et al. [19] and Franke et al. [20]. It has been validated for EWC in cascade tests by Hergt et al. [21]. The transition model used is the $\gamma-\operatorname{Re}_{\Theta}$ model described by Marciniak et al. [22].

Of course, when optimizing a specific compressor, the blade shape and the endwall can be designed together at the same time. Here both tasks were conducted after each other in order to better separate and understand the specific effects.

\subsection{Airfoil Optimization}

In the first step a new airfoil was designed by optimization with AutoOpti. As the base geometry, a NACA airfoil was used. Its features are described in Table 1.

Table 1. Properties of the investigated NACA blade cascade.

\begin{tabular}{cc}
\hline Variable & NACA-65 K48 Airfoil \\
\hline$L$ & $70 \mathrm{~mm}$ \\
$t / L$ & 0.55 \\
$H / L$ & 2.4 \\
$\alpha_{1, A D P}$ & $42^{\circ}$ \\
$\alpha_{S}$ & $22.5^{\circ}$ \\
$M_{i}$ & 0.67 \\
\hline
\end{tabular}

In Figure 2 the operating range of the blade cascade is shown, which has already been numerically and experimentally investigated in the DLR Berlin subsonic cascade wind tunnel by Hergt [23]. As future experiments are now planned for the transonic cascade wind tunnel (TGK) at DLR Cologne, in contrast to the work of Hergt [23] the profiles now have a chord length of $70 \mathrm{~mm}$. In the study by Reutter et al. [13] the numerical operating point at $44^{\circ}$ inflow angle showed the lowest loss, so in this study the same operating point was chosen as the design point and called operating point 0 (OP0). The operating range, shown in Figure 2, is the operating range defined by the almost linear range of the static pressure ratio versus the inflow angle. In this operating range two further operating points are chosen for the airfoil optimization so that the optimization does not only take the design point into account, but tries to keep an operating range which is at least as large as that of the NACA airfoil. Operating point $1(\mathrm{OP} 1)$ is more towards choke at an inflow angle of $38^{\circ}$, while operating point $2(\mathrm{OP} 2)$ is towards stall at an inflow angle of $51^{\circ}$. OP2 is the last point at which the airfoil still raises the static pressure ratio with incidence; 2.7 times the OP0 design loss is found for the NACA mid-section at inlet flow angles corresponding to operating points OP1 and OP2.

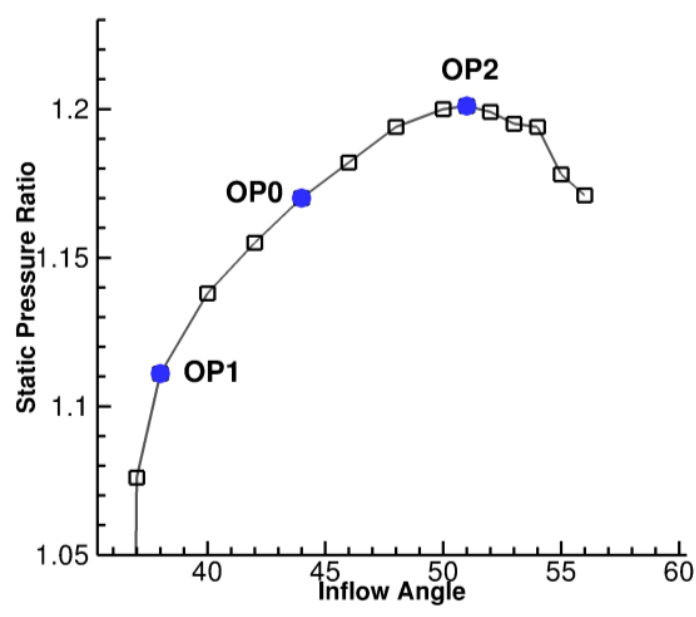

Figure 2. Static pressure ratio versus the inflow angle for the NACA airfoil. 
The optimization aimed at reducing the losses in the three chosen operating points. Two objective functions were used in the optimization. As OP0 is the design point, the first fitness function aimed at reducing the losses there:

$$
\mathrm{F} 1=\omega_{O P 0}
$$

where $\omega$ is the total pressure loss coefficient.

The other fitness function was the mean value of the losses in the other operating points:

$$
\mathrm{F} 2=\left(\omega_{\mathrm{OP} 1}+\omega_{\mathrm{OP} 2}\right) / 2
$$

Additionally, regions of interest were used, which means that certain results have to stay in a specified region. In this way the outflow angle was constricted to be in the region of $0^{\circ}$ to $6^{\circ}$. This ensured an equal or larger turning than the NACA airfoil, which had an outflow angle of $6^{\circ}$. Additionally, at all three operating points, the losses had to be less than the losses of the NACA airfoil in the corresponding operating point.

During the optimization 26 free parameters were used to vary the geometry. Eight parameters each were used to describe the suction and the pressure side by deBoor points. One parameter controlled the stagger angle, one the trailing and leading edge angle, and four angles controlled the transition of the edges to the sides of the blade. The thicknesses of the leading and trailing edge, as well as the elliptical form of the leading edge, were controlled by separate parameters. More details about the airfoil parameters can be found in Lengyel et al. [24].

The optimization was carried out on the 2D airfoil only, using the MISES flow solver. Using 2D calculations is rather economic, so that a typical calculation takes 30 to $60 \mathrm{~s}$ on one core of a modern workstation.

\subsection{Endwall Optimization}

The endwall optimization was carried out similar to Reutter et al. [13], but the optimized airfoil DLR SC14-067A (DLR) was used instead of NACA. The operating points were the same ones as in Reutter et al. [13], being at OP0 $44^{\circ}, \mathrm{OP} 138^{\circ}$, and OP2 $52^{\circ}$. Thus, in contrast to the airfoil MISES optimization, where the OP2 is chosen at $51^{\circ}$ for the endwall optimization, the OP2 is chosen at $52^{\circ}$ due to the larger operating range of the full cascade compared to the airfoil 2D midsection.

A constant inflow angle $\alpha_{1}$ from the sidewall to midspan was used. Thereby the numerical results can be put in relation to the former numerical and experimental cascade investigations [23] and the results obtained here can be validated in future experiments in the TGK. This is in contrast to the inflow condition of a stator near the hub or shroud downstream of a rotor in real turbomachinery applications. The inflow distribution showed a distribution in total pressure corresponding to the typical measured inlet profile of the TGK, which keeps this study close to the intended measurements. The boundary layer on the endwall has a thickness of about $14 \%$ of the half-blade height at the inlet. This is a typical value for compressor flow, even though in rear stages even thicker boundary layers can be encountered.

Two fitness functions were used in the endwall optimization. The first fitness function is:

$$
\mathrm{f}_{1}=0.5 \cdot \omega_{O P 0} \cdot+0.25 \cdot \omega_{O P 1}+0.25 \cdot \omega_{O P 2}
$$

It is used to reduce the losses in all three operating points.

The second fitness function is an area-weighted mean of the quadratic deviation from the reference outflow angle. Here 62 cells were used for the mesh in spanwise direction:

$$
\mathrm{f}_{2}=\frac{\mathrm{r}}{\mathrm{H}}(1) \cdot\left[\alpha(1)-\alpha_{\mathrm{ref}}\right]^{2}+\sum_{62}^{\mathrm{k}=2}\left[\frac{\mathrm{r}}{\mathrm{H}}(\mathrm{k})-\frac{\mathrm{r}}{\mathrm{H}}(\mathrm{k}-1)\right] \cdot\left[\alpha(\mathrm{k})-\alpha_{\mathrm{ref}}\right]^{2}
$$


By using the quadratic angle deviation, both negative and positive deviations are punished in this fitness function, as well as larger deviations, more than smaller ones. It is used to homogenize the outflow angle at the operating point OP0. The reference angle $\alpha_{\text {ref }}$ is $4.06^{\circ}$, which is the midsection value of the outflow angle in the reference case. In Figure 3, which shows the outflow distribution of the reference cascade, it is marked by a straight red line. Near the endwall a strong overturning can be noticed, while between $4 \%$ and $35 \%$ span an underturning occurs. This is typical for a cascade with a strong secondary flow.

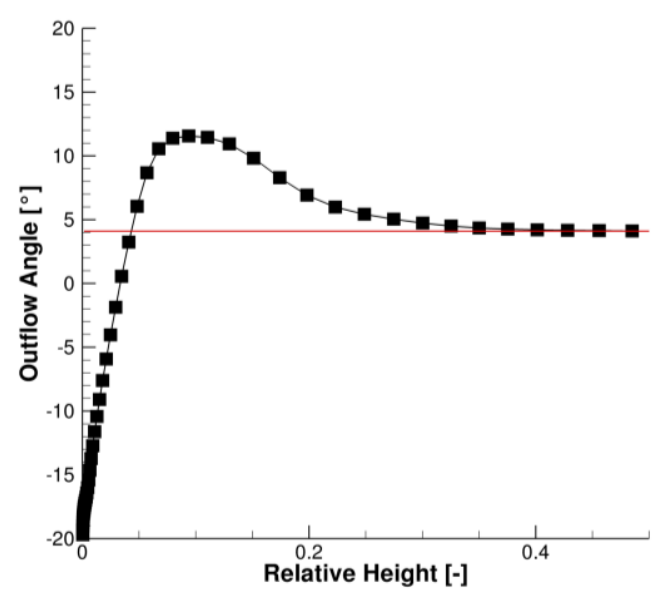

Figure 3. Outflow angle distribution of the DLR blade.

The endwall is described by the same parameters as in the endwall optimization in the study of Reutter et al. [13], where 26 parameters were used to vary the endwall. The parametrization is shown in Figure 4. Each green dot is a parameter which can vary in height. At the entry, the LE, the TE, and the exit at the first and last points of the lines are the same to give a smooth endwall without edges. First, splines are defined by these rows of points (see Figure 4), then a NURBS (Non-uniform rational B-Splines) surface is defined by these lines.

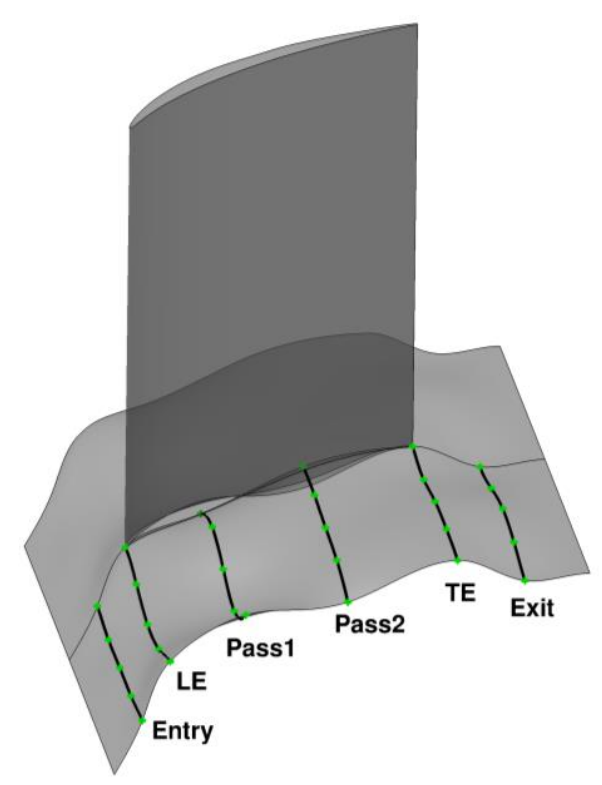

Figure 4. Endwall contouring (EWC): The six splines consisting of the control points, which define the endwall. The endwall and the blade (up to midspan) are depicted as semi-transparent. 


\section{Results}

\subsection{Airfoil Optimization}

The airfoil optimization, shown in Figure 5, exhibited a clear Pareto front, from which a geometry was chosen as the base airfoil geometry for the endwall optimization. It is called DLR SC14-067A.

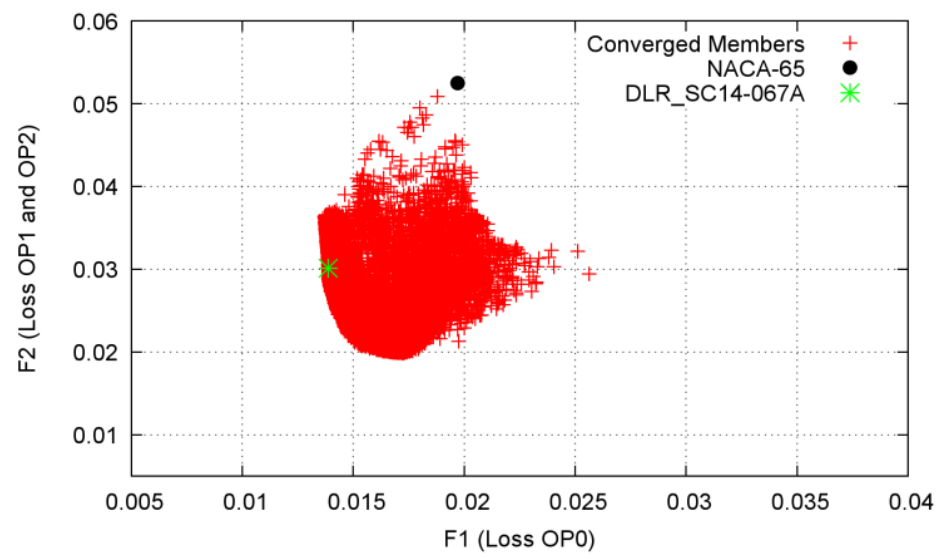

Figure 5. Pareto front of the airfoil optimization. The DLR geometry is marked on the Pareto front.

The chosen DLR geometry shows a significant improvement in the loss in OP0 and also in the combined losses in OP1 and OP2. Figure 6 shows the geometry of the base NACA airfoil and the optimized DLR airfoil. On the right hand side a zoom of the leading edge is shown, which shows that the leading edge is similar, the region directly after the leading edge is thicker than the NACA airfoil. Compared to the base NACA airfoil, the DLR airfoil has a reduced stagger angle by $5^{\circ}$, the leading edge angle changed only by $1^{\circ}$, and the trailing edge angle changed by $6^{\circ}$. The value of the leading edge radius increased but, at the same time, the leading edge ellipse became sharper. This parameter was also restricted so that the ratio of the axis is no greater than 2, which is the limit against which the optimization converged. The trailing edge radius was not allowed to become smaller than $0.3 \%$ of the chord length, which is the value against which it converged, starting from the NACA airfoil with $0.55 \%$.
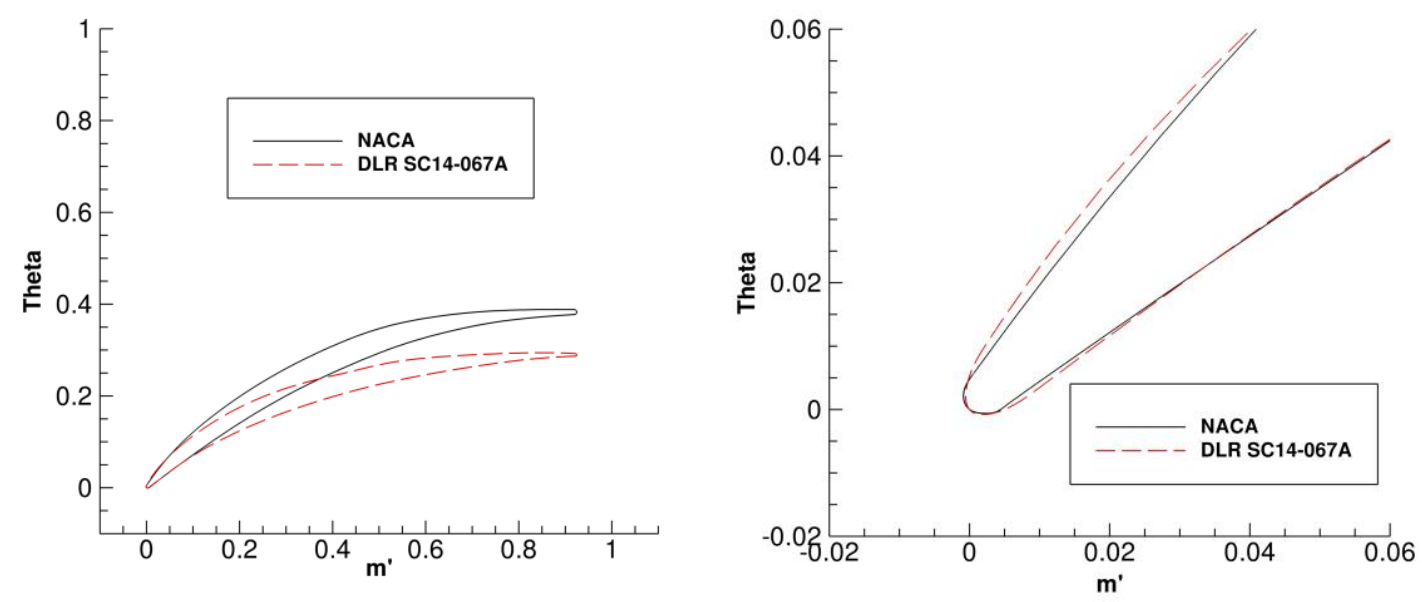

Figure 6. Geometry (left): DLR (dashed red line) and NACA (black line), leading edge detail (right).

The profile section isentropic Mach number distribution is shown in Figure 7, left. It can be seen that the DLR airfoil shows a more frontloaded design, often seen in new airfoil development projects, such as Siemens HPA-Airfoils (see Köller et al. [25] and Küsters et al. [26]). It is still subsonic in OP0. 
On the right hand side of Figure 7 the shape factors for the two airfoils are shown. It can be seen that the pressure side of the optimized airfoil stays laminar, where the NACA airfoil is turbulent, while, on the suction side, the transition of the DLR airfoil already occurs at $20 \%$ chord length compared to $30 \%$ for the NACA airfoil. In Figure 8 the friction factor shows that the values are low, but positive, over the whole length of the airfoils. On the right hand side, the loss-incidence characteristics show that in the MISES 2D-calculations the aim of the optimization is clearly reached to design an airfoil with lower losses over the whole operating range compared to the NACA airfoil. Thus, the DLR SC14-067A geometry was used as the basis for the following endwall optimization.
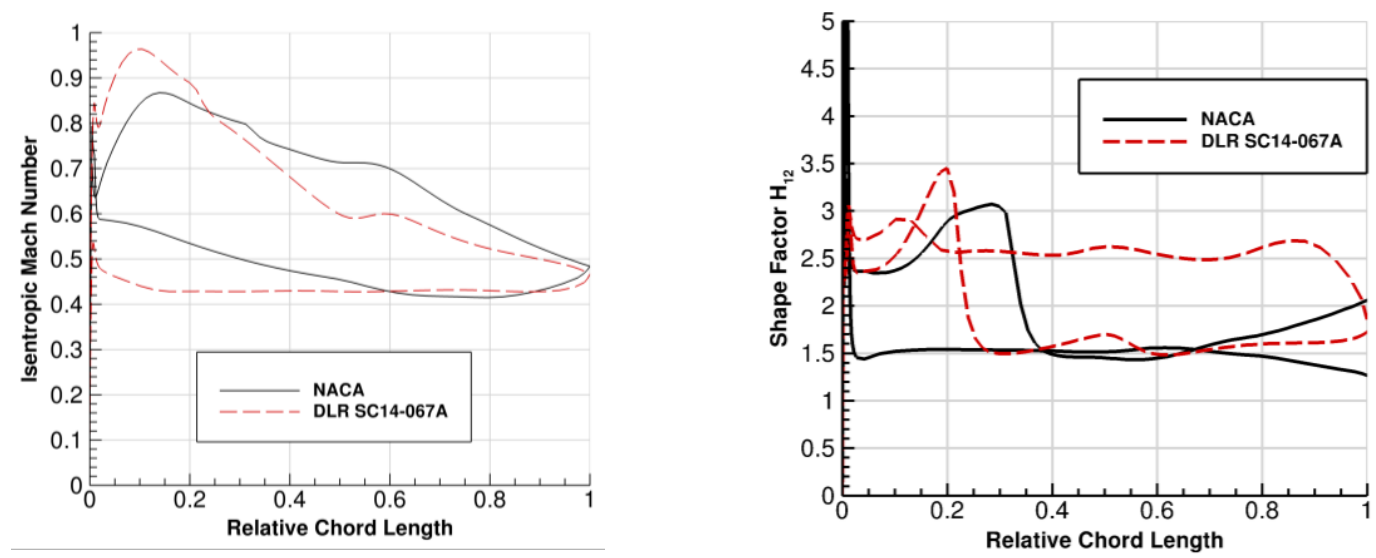

Figure 7. OP0: Isentropic Mach number distribution NACA (black line) and DLR (dashed red line) (left); and the shape factor (right).
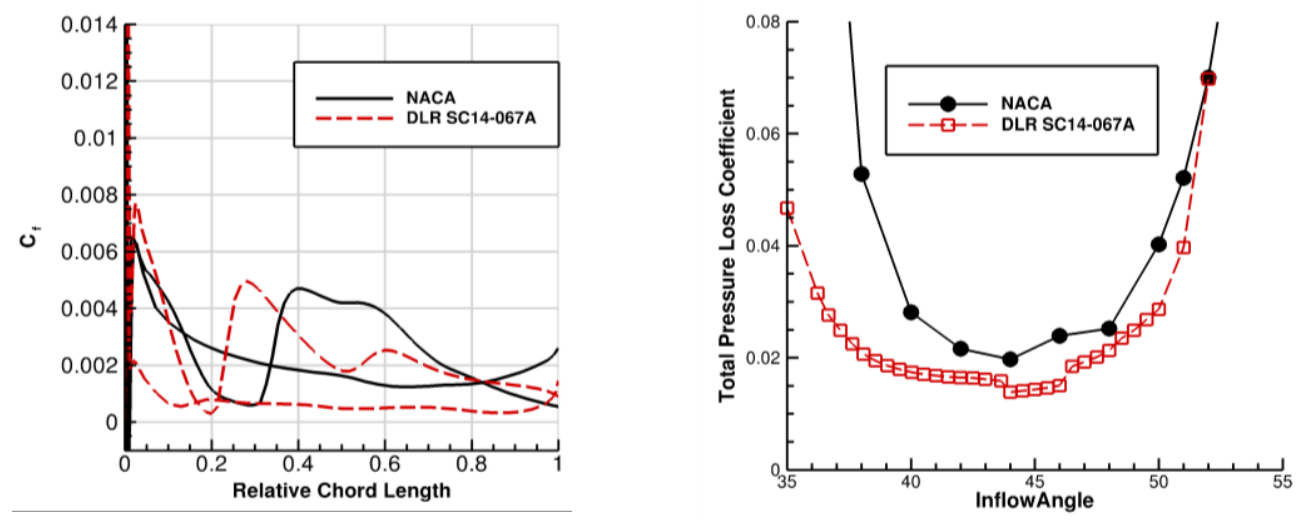

Figure 8. Wall shear coefficient for the optimized (dashed red line) and NACA (black line) airfoil (left) for OP0; loss-incidence characteristics (right).

The geometry was then studied in a cascade configuration where the 3D blades are modelled together with the smooth endwall and the constant fillet in the 3D flow solver TRACE, including a transition model. The results are shown in Figure 9. One can clearly see that the losses at midspan are close to the results of the MISES calculations (see the direct comparison for the optimized airfoil in Figure 9, right), while the results for the whole cascade are much higher in losses, because of the endwall losses. The whole behavior of the DLR is different from the NACA cascade in the investigated angle range. The 3D losses are close to each other at positive incidence, but the smallest losses for the DLR airfoil occur at negative incidence in the investigated operating range and are much lower (solid symbols in Figure 9, left). 

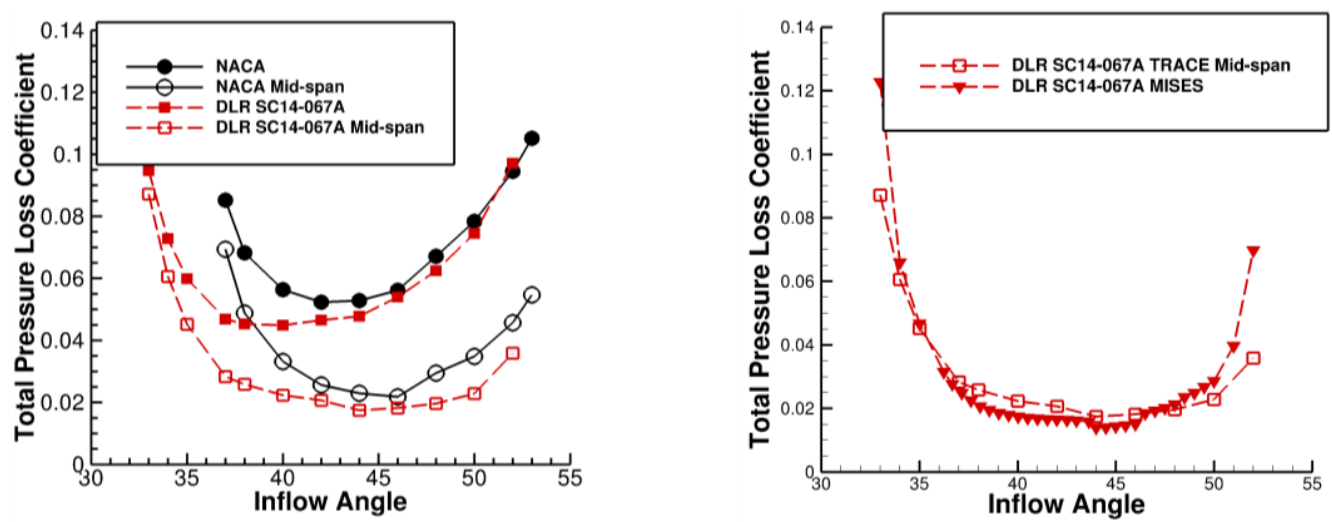

Figure 9. Inflow-angle-loss-characteristics for NACA and DLR cascade. TRACE full cascade vs. TRACE midspan (left), and MISES vs. TRACE midspan loss for the DLR cascade (right).

\subsection{Endwall Optimization}

The optimized DLR profile section with smooth endwalls and a fillet was used as a reference and starting geometry.

Figure 10 shows the converged members of this optimization. A restriction on the resulting geometries was imposed that, in the region where the underturning of the DLR blade occurs, the new geometries should not have a stronger underturning at any point of the outflow angle distribution. This restriction was imposed in contrast to the study of Reutter et al. [13] because it was found that only using the fitness function 2 was not enough to omit geometries, which showed larger underturnings in a small region. A further restriction was that the total pressure loss coefficient had to be less than that of the base geometry with a smooth endwall in the corresponding operating point. Optimized member 555 was chosen from the Pareto front for further discussion.

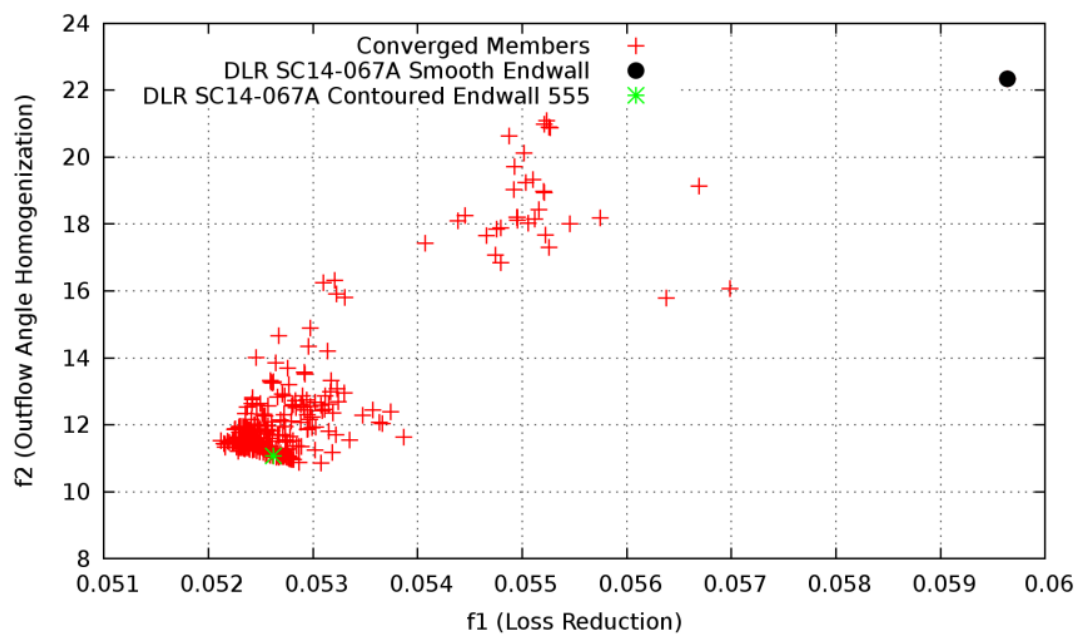

Figure 10. Geometries with the evolved Pareto front of the endwall optimization of the DLR cascade.

Figure 11 shows the optimized endwall member 555 as a contour plot and as a 3D view. There is a groove along the suction side, as already observed by Dorfner $[9,10]$, and a hill and valley structure behind the blade, as already observed by Reutter et al. [13]. The valley near the suction side reduced the Mach number level, whereas the hill near the pressure side increased it. The cross-passage gradient was, thus, reduced. At the inlet a further hill increases the leading edge fillet, which helps to control the horseshoe vortex. 

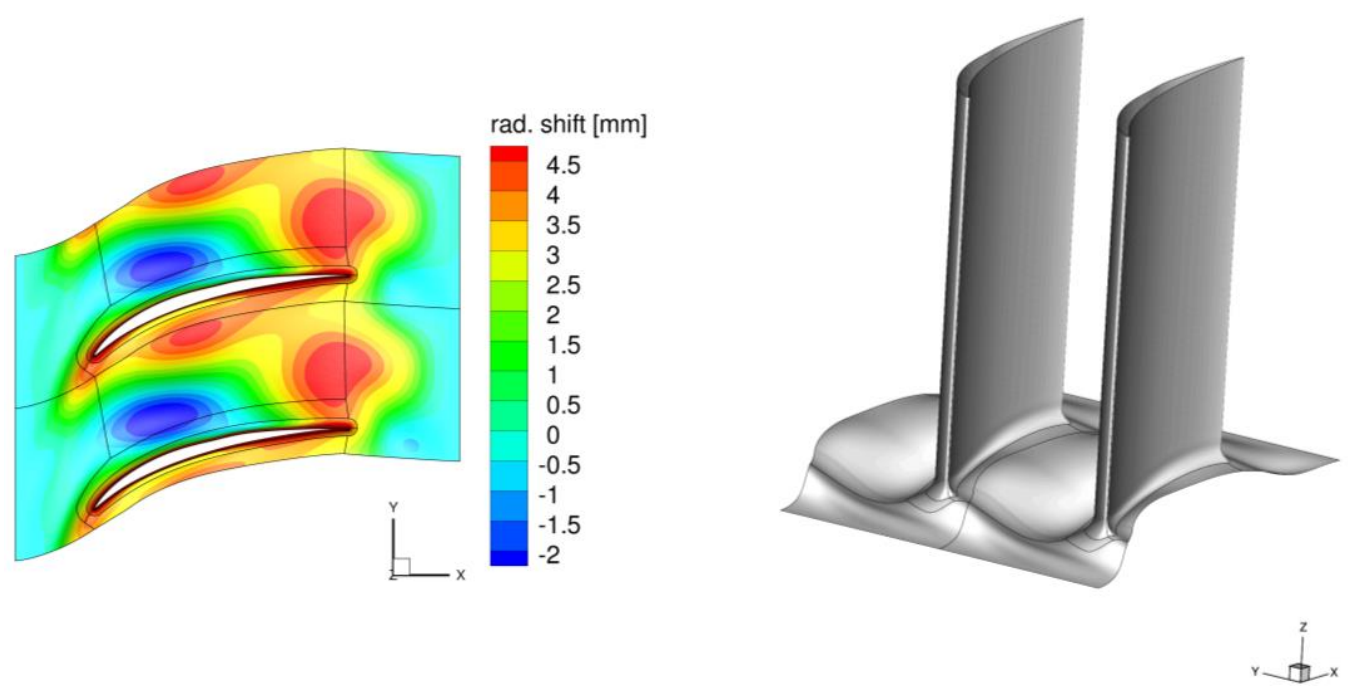

Figure 11. Height contour plot of the optimized contour member 555 (left); and a 3D view looking onto the leading edge (right).

The optimization homogenized the outflow in all three operating points (see Figure 12). All graphs show the distributions over the relative mass flow $\mathrm{m} / \mathrm{M}$, and only up to $50 \%$ relative mass flow, as the calculations were conducted symmetrically. EWC redirected the endwall flow, thus the overturning was typically reduced by $5^{\circ}$ and the underturning by $1^{\circ}$. The same effects as explained in Reutter et al. [13] can be found here; that the corner stall is reduced and the hill and valley structure at the end of the blade helps to homogenize the outflow. However, in contrast to Reutter et al. [13], where this endwall optimization was performed using the NACA airfoil, now with the DLR geometry there is no loss reduction at mid-span, because the airfoil is already very good.
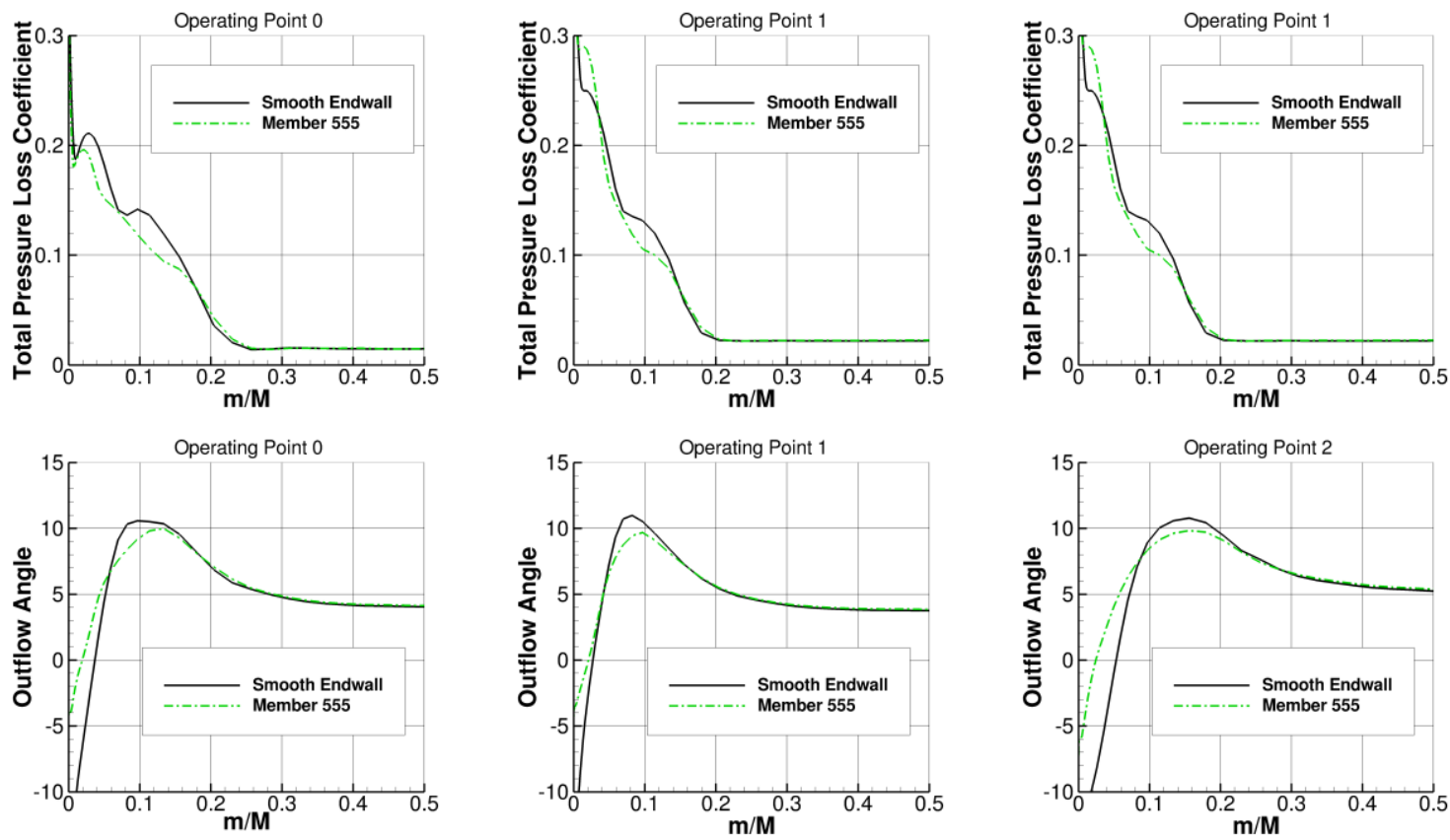

Figure 12. Loss coefficient and outflow angle for the three specified operating points.

Looking at the total values for the losses, in fact the losses were reduced relatively for OP1 by $0.5 \%$, for OP0 by $9.1 \%$, and for OP2 by $16.1 \%$ (see Figure 13 ). 


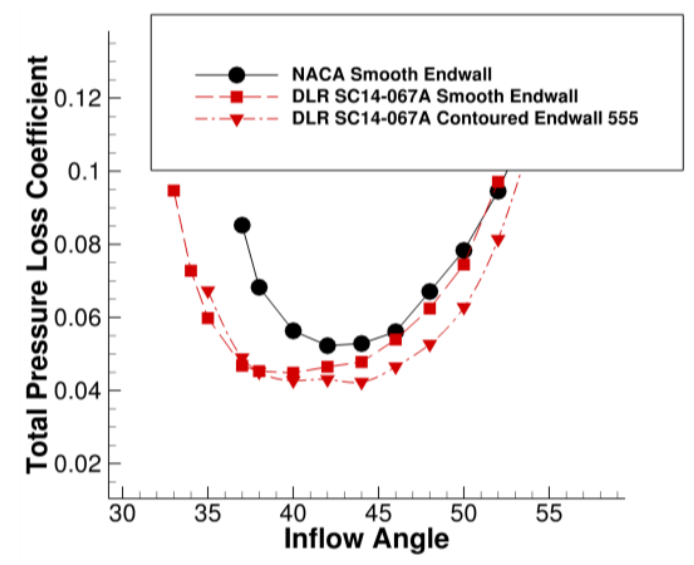

Figure 13. Loss-inflow-angle-characteristics for NACA and DLR cascades with smooth endwalls vs. DLR cascade with the optimized endwall.

\section{Conclusions}

The NACA profile was optimized in 2D with MISES and used for optimization of non-symmetrical EWC with the RANS-solver TRACE. Only simulations are given. EWC shifted the stall incidence. A hill and valley structure was found by the optimization: one hill to make the leading edge longer, a hill and valley combination in the passage to reduce losses, and a hill at the trailing edge to reduce overturning. The height of the EWC varied between $+2.5 \%$ (hills) and $-1.2 \%$ (valleys) of blade height. EWC gave a shifted choke incidence of the DLR airfoil by -4 degrees and a stall incidence by 2 degrees, allowing for between $0.5 \%$ and $16 \%$ total loss reduction for the three specified OPs at improved exit flow quality. Mid-section improvements reported for NACA are not found for the DLR cascade, allowing the optimizer to fully concentrate on improving endwall flow. Only with a well-defined mid-section did the effects of EWC stay in the lower $30 \%$ of the span, and a positive effect can be seen on turning and losses. Thus, EWC is also beneficial and useful in modern designs.

For the future, wind tunnel tests are planned to verify the effects observed in simulations for the optimized airfoil and EWC. Furthermore, based on these results, a design study is planned to transfer the results into a compressor application and see, e.g., how the downstream blade row can benefit from the homogenized flow angle distribution.

Acknowledgments: The authors would like to thank the German Aerospace Center (DLR) for the opportunity to do research at DLR.

Author Contributions: O.R, A.H., and E.N. designed this study and the optimizations. M.R. helped to set up and control the optimizations and analyze the data. O.R., A.H., and E.N. analyzed the data. O.R. wrote the paper.

Conflicts of Interest: The authors declare no conflict of interest. The founding sponsors had no role in the design of the study; in the collection, analyses, or interpretation of data; in the writing of the manuscript, and in the decision to publish the results.

\section{Nomenclature}

$\begin{array}{ll}\text { ADP } & \text { Aerodynamic design point } \\ \text { BC } & \text { Boundary condition } \\ C_{\mathrm{f}} & \text { Wall shear stress coefficient } \\ \text { DLR SC14-067A } & \text { DLR Subsonic Cascade designed in 2014 with } M_{i}=0.67 \\ \text { EWC } & \text { Endwall contouring } \\ f 1, f 2 & \text { Fitness functions for the endwall optimization } \\ F 1, F 2 & \text { Fitness functions for the airfoil optimization } \\ H & \text { Blade height }(\mathrm{m}) \\ L & \text { Chord length }(\mathrm{m}) \\ \text { LE } & \text { Leading edge }\end{array}$




$\begin{array}{ll}m / M & \text { Relative mass flow }(-) \\ m & \text { Coordinate along a streamline }(\mathrm{m}) \\ m^{\prime} & \text { Weighted length along the streamline } \mathrm{m}^{\prime}=\int \mathrm{dm} / \mathrm{r}(-) \\ M_{i} & \text { Mach number at inflow }(-) \\ \text { OP } & \text { Operating point } \\ r & \text { Coordinate in blade height direction, radius }(\mathrm{m}) \\ t & \text { Pitch }(\mathrm{m}) \\ \text { TE } & \text { Trailing edge } \\ \text { TGK } & \text { Transonic Cascade Test Facility at DLR Cologne } \\ x, y, z & \text { Cartesian coordinates }(\mathrm{m}) \\ \alpha & \text { Outflow angle }\left(^{\circ}\right) \\ \alpha_{r e f} & \text { Outflow angle of the reference }\left(^{\circ}\right) \\ \alpha_{1} & \text { Inflow angle }\left(^{\circ}\right) \\ \alpha_{S} & \text { Stagger angle }\left(^{\circ}\right) \\ \Theta & \text { Circumferential angle coordinate }(\mathrm{rad}) \\ \omega & \text { Total pressure loss coefficient }(-)\end{array}$

\section{References}

1. Scholz, N. Ueber den Einfluss der Schaufelhoehe auf die Randverluste in Schaufelgittern. Forsch. Geb. Ingenieurwes. A 1954, 20, 155-157. [CrossRef]

2. Spear, D.A.; Biederman, B.P. Flow Directing Assembly for the Compression Section of a Rotary Machine. U.S. Patent 5,397,215, 14 March 1995.

3. Hoeger, M.; Schmidt-Eisenlohr, U. Rotary Turbomachine Having a Transonic Compressor Stage. U.S. Patent 6,017,186, 25 January 2000.

4. Harvey, N.W. Some effects of non-axisymmetric end wall profiling on axial flow compressor aerodynamics: Part I-Linear cascade investigation. In Proceedings of the ASME Turbo Expo 2008: Power for Land, Sea, and Air, Berlin, Germany, 9-13 June 2008; pp. 543-555.

5. Harvey, N.W.; Offord, T.P. Some effects of non-axisymmetric end wall profiling on axial flow compressor aerodynamics: Part II-Multi-stage HPC CFD study. In Proceedings of the ASME Turbo Expo 2008: Power for Land, Sea, and Air, Berlin, Germany, 9-13 June 2008; pp. 557-569.

6. Iliopoulou, V.; Lepot, I.; Geuzaine, P. Design optimization of a HP compressor rotor blade and its hub endwall. In Proceedings of the ASME Turbo Expo 2008: Power for Land, Sea, and Air, Berlin, Germany, 9-13 June 2008; pp. 2197-2208.

7. Reising, S.; Schiffer, H.P. Non-axisymmetric end wall profiling in transonic compressors part I: Improving the static pressure recovery at off-design conditions by sequential hub and shroud end wall profiling. In Proceedings of the ASME Turbo Expo 2009: Power for Land, Sea, and Air, Orlando, FL, USA, 8-12 June 2009.

8. Reising, S.; Schiffer, H.P. Non-axisymmetric end wall profiling in transonic compressors part II: Design study of a transonic compressor rotor using nonaxisymmetric end walls-optimization strategies and performance. In Proceedings of the ASME Turbo Expo 2009: Power for Land, Sea, and Air, Orlando, FL, USA, 8-12 June 2009.

9. Dorfner, C. Entwicklung eines Verfahrens zur Konstruktion Nicht-Rotationssym-Metrischer Seitenwand-Konturen in Axialen Verdichtern. Ph.D. Thesis, University Bochum, Bochum, Germany, 2009.

10. Dorfner, C.; Hergt, A.; Nicke, E.; Moenig, R. Advanced non-axisymmetric endwall contouring for axial compressors by generating an aerodynamic separator-Part I: Principal cascade design and compressor application. J. Turbomach. 2011, 133, 021026. [CrossRef]

11. Heinichen, F.; Guemmer, V.; Plas, A.; Schiffer, H.-P. Numerical investigation of the influence of non-axisymmetric hub contouring on the performance of a shrouded axial compressor stator. CEAS Aeronaut. J. 2011, 2, 89-98. [CrossRef]

12. Gier, J.; Ardey, S.; Eymann, S.; Reinmoeller, U.; Niehuis, R. Improving 3D flow characteristics in a multistage LP turbine by means of endwall contouring and airfoil design modification-Part 2: Numerical simulation and analysis. In Proceedings of the ASME Turbo Expo 2002: Power for Land, Sea, and Air, Amsterdam, The Netherlands, 3-6 June 2002. 
13. Reutter, O.; Hemmert-Pottman, S.; Hergt, A.; Nicke, E. Endwall Contouring and Fillet Design for Reducing Losses and Homogenizing the Outflow of a Compressor Cascade. In Proceedings of the ASME Turbo Expo 2014: Turbine Technical Conference and Exposition, Düsseldorf, Germany, 16-20 June 2014.

14. Voss, C.; Aulich, M.; Kaplan, B.; Nicke, E. Automated multiobjective optimisation in axial compressor blade design. In Proceedings of the ASME Turbo Expo 2006: Power for Land, Sea, and Air, Barcelona, Spain, 8-11 May 2006.

15. Siller, U.; Voss, C.; Nicke, E. Automated multidisciplinary optimization of a transonic axial compressor. In Proceedings of the 47th AIAA Aerospace Sciences Meeting including The New Horizons Forum and Aerospace Exposition, Orlando, FL, USA, 5-8 January 2009.

16. Aulich, M.; Siller, U. High-dimensional constrained multiobjective optimization of a fan stage. In Proceedings of the ASME 2011 Turbo Expo: Turbine Technical Conference and Exposition, Vancouver, BC, Canada, 6-10 June 2011; pp. 1185-1196.

17. Voss, C.; Aulich, M.; Raitor, T. Metamodel Assisted Aeromechanical Optimization of a Transonic Centrifugal Compressor. In Proceedings of the ISROMAC 2014, Honolulu, HI, USA, 24-28 February 2014.

18. Youngren, H.; Drela, M. Viscous/Inviscid method for preliminary design of transonic cascades. In Proceedings of the 27th Joint Propulsion Conference, Sacramento, CA, USA, 24-26 June 1991.

19. Becker, K.; Heitkamp, K.; Kuegeler, E. Recent progress in a hybrid-grid CFD solver for turbomachinery flows. In Proceedings of the 5th European Conference on Computational Fluid Dynamics, ECOMAS CFD 2010, Lisbon, Portugal, 14-17 June 2010.

20. Franke, M.; Roeber, T.; Kuegeler, E.; Ashcroft, G. Turbulence treatment in steady and unsteady turbomachinery flows. In Proceedings of the 5th European Conference on CFD, Lisbon, Portugal, 14-17 June 2010.

21. Hergt, A.; Dorfner, C.; Steinert, W.; Nicke, E.; Schreiber, H.-A. Advanced nonaxisymmetric endwall contouring for axial compressors by generating an aerodynamic separator-Part II: Experimental and numerical cascade investigation. J. Turbomach. 2011, 133, 021027. [CrossRef]

22. Marciniak, V.; Weber, A.; Kügeler, E. Modelling transition for the design of modern axial turbomachines. In Proceedings of the 6th European Conference on Computational Fluid Dynamics, Barcelona, Spain, 20-25 July 2014.

23. Hergt, A. Ueber grenzschichtbeeinflussende Maßnahmen in den Randzonen von Verdichtergittern. Ph.D. Thesis, Technical University Berlin, Berlin, Germany, 2011.

24. Lengyel, T.; Schmidt, T.; Voß, C.; Nicke, E. Design of a counter rotating fan-An aircraft engine technology to reduce noise and CO2-emissions. In Proceedings of the 19th ISABE Conference Montral/Canada 2009, Montreal, QC, Canada, 8-12 September 2009.

25. Köller, U.; Mönig, R.; Küsters, B.; Schreiber, H.-A. Development of advanced compressor airfoils for heavy-duty gas turbines-part I: Design and optimization. ASME J. Turbomach. 2000, 122, 397-405.

26. Küsters, B.; Schreiber, H.-A.; Köller, U.; Mönig, R. Development of advanced compressor airfoils for heavy-duty gas turbines-part II: Experimental and theoretical analysis. ASME J. Turbomach. 2000, 122, 406-414.

(C) 2017 by the authors. Licensee MDPI, Basel, Switzerland. This article is an open access article distributed under the terms and conditions of the Creative Commons Attribution (CC BY NC ND) license (https://creativecommons.org/licenses/by-nc-nd/4.0/). 